Earth and Planetary Science Letters, 28 (1975) 1-12

(c) Elsevier Scientific Publishing Company, Amsterdam - Printed in The Netherlands

\title{
ON THE MAGNETIC SUSCEPTIBILITY ANISOTROPY OF DEEP-SEA SEDIMENT ${ }^{1,2}$
}

\author{
DENNIS V. KENT \\ Lamont-Doherty Geological Observatory of Columbia University, Palisades, N.Y. (USA) \\ and \\ WILLIAM LOWRIE \\ Institut für Geophysik, ETH, Zürich (Switzerland) \\ Received April 28, 1975 \\ Revised version received August 21, 1975
}

\begin{abstract}
Susceptibility anisotropies in the form of vertically prolate ellipsoids have been reported in many deep-sea sediment cores. The results of the present investigation suggest that these anisotropies may not describe the original magnetic fabric of deep-sea sediment, but are more likely due to either a measurement effect or to deformation of the sediment during coring. Anisotropy measurements made on a spinner magnetometer sometimes were found to be greatly affected by the shape of the sample. This apparent "sample-shape effect" was not observed on a low-field torque meter. The anisotropy of samples taken near the base or the top of some piston cores often reflects sediment disturbance during the coring operation. Most samples of deep-sea sediment examined had weak anisotropies that could be interpreted as due to normal depositional processes, including bioturbation. The best-fitting susceptibility ellipsoids were usually oblate with near vertical minimum susceptibility axes.
\end{abstract}

\section{Introduction}

Magnetic susceptibility anisotropy measurements in deep-sea sediment indicate that the dominant form of anisotropy of this material is represented by a prolate susceptibility ellipsoid with a steeply inclined maximum susceptibility axis $[1,2]$. Vertically prolate susceptibility ellipsoids were measured initially in several specimens from two Indian Ocean deep-sea sediment cores by Harrison and Peterson [1] and subsequently in most of 120 specimens from 18 deep-sea sediment cores from several oceans by $L \varnothing$ lie et al. [2]. Harrison and Peterson interpreted the observed anisotropies as due to in-situ formation of magnetic minerals whereas Løvlie et al. thought they resulted from soft sediment deformation during the coring process.

\footnotetext{
1 L-DGO Contribution No. 2266.

2 Institut für Geophysik Contribution No. 119.
}

Magnetic susceptibility anisotropy measurements made on other natural and laboratory-deposited sediment have established the characteristics of primary magnetic fabric [3-5]. There is commonly a wellmarked magnetic foliation in or near to the bedding plane; the shape of the susceptibility ellipsoid is oblate with a near-vertical minimum susceptibility axis. Such a magnetic fabric is attributed to the effect of gravity in bringing the long axes of magnetic grains as near as possible to the horizontal plane at the instant of deposition. A magnetic lineation may be present within the foliation plane due to partial alignment of long axes of magnetic grains by water currents [6], effects on a depositional slope [7] or perhaps in some cases by the earth's magnetic field [8]. Normal depositional processes can, therefore, account for the characteristics of a primary magnetic fabric.

Sediment magnetic fabrics, whose characteristics differ to various extents from those considered to be of depositional or primary origin, often result from 
modification of an initial primary fabric. It has been recognized that tectonic deformation results in a systematic modification of a primary fabric that is related to the nature of the mechanical deformation. For example, Graham [9] found that the susceptibility anisotropy of Paleozoic sedimentary rocks in the Appalachians changed from a primary fabric in flat-lying beds to magnetic fabrics in deformed beds which were related systematically to the structural setting. On the other hand, the action of burrowing organisms in sediment will tend to randomize any preferred original arrangement of grains so that the primary fabric is eventually destroyed. The residual susceptibility anisotropy observed in sediment thoroughly affected by burrowing may be characterized by relatively small anisotropies and scattered directions of the principal susceptibility axes, and may be unrelated to any primary magnetic fabric [10].

The vertically prolate susceptibility anisotropies observed in deep-sea sediments are significant in that their apparent consistency and wide deviation from anisotropies resulting from normal depositional processes imply an anomalous, common history for these sediments. However, no systematic process has been recognized as endemic to deep-sea sediments which can explain satisfactorily these anisotropy observations. In addition, any proposed exceptional history must account for the presence of natural remanent magnetization (NRM) in deep-sea sediments which usually provides a reliable record of the earth's magnetic field [11]. The purpose of this paper is to present additional data on the susceptibility anisotropy of some deep-sea sediments and to re-examine its origin, measurement and significance.

\section{Measurement and computational techniques}

The measurement techniques and the method of calculation of anisotropy assume [3] that the susceptibility can be approximated by a second rank symmetric tensor $K_{i j}$ which linearly relates the induced magne tization component $J_{i}$ to each component $H_{j}$ of the field:

$J_{i}=K_{i j} H_{j}$

The magnetic susceptibility anisotropy of sediment specimens was first measured with a PAR-SMl spinner magnetometer in which the specimen is spun in a small steady field at $52.5 \mathrm{~Hz}$, one-half the frequency used for remanence measurements. This produces a signal having twice the rotation frequency and magnitude proportional to the applied field and to the tensor elements $K_{i i}, K_{i j}$ and $K_{i j}$ in the plane perpendicular to the rotation axis. The in-phase signal is proportional to $\left(K_{i i}-K_{j j}\right)$ and the quadrature component to $K_{i j}$ [12].

The alternative method of anisotropy measurement used a low-field torque instrument similar to that described by King and Rees [13]. A specimen is suspended by a thin phosphor-bronze fiber at the center of a Helmholtz coil whose axis is horizontal. A specimen with an anisotropic susceptibility experiences a torque in the alternating field produced by the coil. The torque measured by the deflection of a light spot on a scale, is proportional to the square of the alternating field strength and to the anisotropy in the plane of measurement.

The susceptibility may be specified completely by six quantities, three relating to the magnitudes of the principal axes ( $K_{\max }, K_{\text {int }}$ and $\left.K_{\min }\right)$ and three relating to their directions which are orthogonal. In either the spinner or torque meter method of measurement, susceptibility differences are measured and a separate measurement of bulk susceptibility is made on an AC bridge in a particular specimen direction to determine the magnitudes of the principal susceptibility axes.

A check on the reliability of the measured data is obtained by producing more data than are needed to describe the susceptibility anisotropy. The best data values are found by a least-squares fit; the differences between these optimized values for the susceptibility tensor and the original readings are calculated and an estimate of the data reliability is made from the root mean square (RMS) value of these residuals. In the specimens measured here, the RMS values of the residuals were generally less than $10-15 \%$ of the RMS optimized values and support the assumption that their susceptibilities are adequately represented by a second order symmetric tensor. However, many specimens produced higher errors and were rejected from further consideration; these high measurement errors may stem from susceptibilities that are more complex than second order, from very weak anisotropies, or a combination of these and other causes [13]. 
Several parameters have been defined to describe the shape of the susceptibility ellipsoids. The parameter [7]:

$q=2\left(K_{\max }-K_{\text {int }}\right) /\left(K_{\max }+K_{\text {int }}-2 K_{\text {min }}\right)$

is a measure of the relative importance of foliar and linear elements in the magnetic fabric. The values of $q$ can range from 0.0 (pure foliation) to 2.0 (pure lineation) with the change from dominantly foliar (oblate) to linear (prolate) elements of fabric at a value of 0.67 . Primary magnetic fabrics in water deposited sediments are dominantly foliar and have values of $q$ that usually range only up to 0.67 [5]. This parameter is useful in that it can be calculated using only the better determined values of susceptibility differences.

The quantity:

$h(\%)=\frac{K_{\max }-K_{\min }}{\left(K_{\max }+K_{\text {int }}+K_{\min }\right) / 3} \times 100$

expresses the anisotropy as a percentage of the average bulk susceptibility. The value of $h$ cannot be determined very precisely since it is directly affected by the higher errors in measurement of bulk susceptibility (compared to the measurement of susceptibility differences). However, $h$ can serve as a useful parameter in at least a qualitative sense for comparative and descriptive purposes.

\section{Spinner magnetometer results}

The paleomagnetic stratigraphy and physical description of a North Pacific core V20-88 were reported by Opdyke and Foster [14] and is summarized in

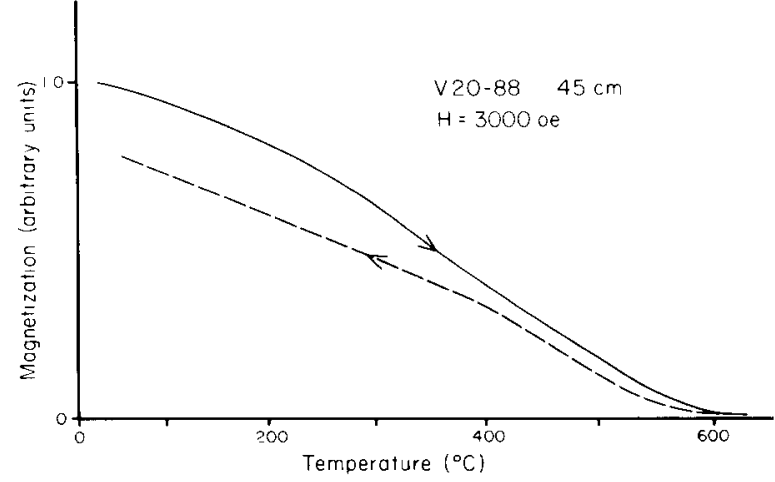

Fig. 1. High-field thermomagnetic curve of magnetic extract from core V20-88. Curie point at $575^{\circ}$ suggests magnetite as dominant magnetic mineral. Analysis performed in air.

Table 1. Thermomagnetic analysis of a magnetic extract from the core indicates that magnetite is the dominant magnetic mineral (Fig. 1) al though nearby cores with similar thermomagnetic curves were interpreted to contain a partially maghemitized form of magnetite [15]. Seventeen specimens were cut from the dried core and fashioned with a phosphor-bronze knife into approximately right-circular cylinders, 2.0 $2.5 \mathrm{~cm}$ in diameter, the cylinder axis of each being parallel to the core axis. Initially, the length to diameter ratio of the specimens was in the range 1.0-1.4 (average 1.12).

The susceptibility anisotropy of each specimen was measured on the PAR-SM1 spinner magnetometer in a direct field of $5.28 \mathrm{Oe}$. The susceptibility ellipsoids were of a type similar to those previously found in other deep-sea sediment cores by Harrison and Peterson [1] and Løvlie et al. [2]. The $K_{\max }$ axes were

TABLE 1

Core locations and descriptions

\begin{tabular}{|c|c|c|c|c|c|}
\hline Core & Lat. & Long. & $\begin{array}{l}\text { Length } \\
(\mathrm{cm})\end{array}$ & $\begin{array}{l}\text { Sedimentation* } \\
\text { rate } \\
\left(\mathrm{cm} / 10^{3} \mathrm{yrs}\right)\end{array}$ & Lithology \\
\hline V20-88 & $40^{\circ} 11^{\prime} \mathrm{N}$ & $151^{\circ} 39^{\prime} \mathrm{W}$ & 850 & 0.2 & brown clay \\
\hline RC11-170 & $44^{\circ} 29^{\prime} \mathrm{N}$ & $163^{\circ} 21^{\prime} \mathrm{W}$ & 1002 & 0.4 & diatomaceous lutite \\
\hline RC14-14 & $35^{\circ} 55^{\prime} \mathrm{S}$ & $59^{\circ} 58^{\prime} \mathrm{E}$ & 2588 & 8.6 & terrigenous mud \\
\hline
\end{tabular}

* Based on magnetic stratigraphy of these cores $[14,16]$. 


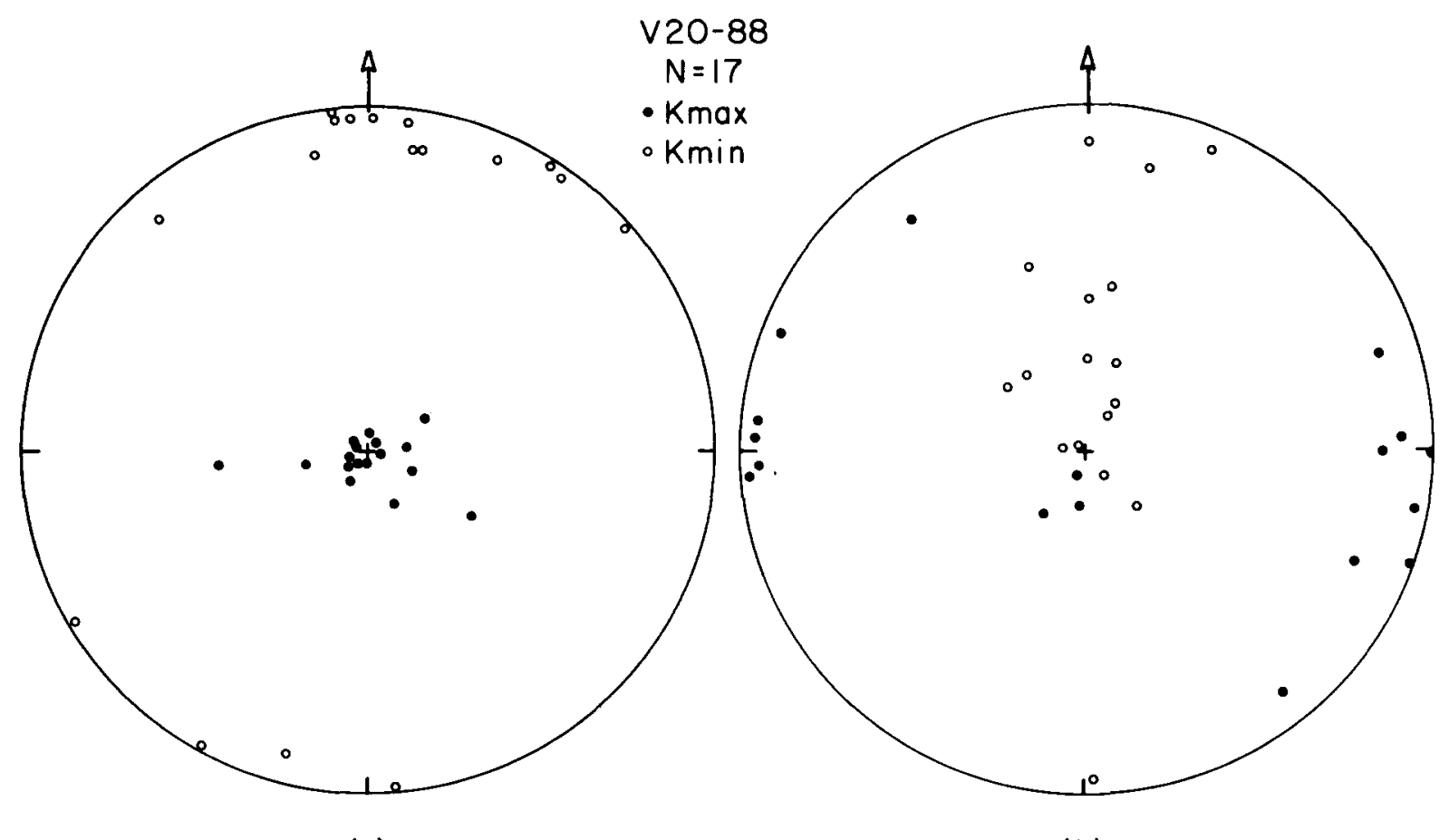

(a)

(b)

Fig. 2. Orientation of maximum $\left(K_{\max }\right)$ and minimum $\left(K_{\min }\right)$ susceptibility axes of specimens from core V20-88. Anisotropies measured on PAR-SM1 spinner magnetometer in 5.28 Oe direct field. (a) Length to diameter ratio of cylinder specimens greater than 1.0. (b) Same specimens but with length to diameter ratios equal to 0.85 . Axes plotted on equal-area projection with primitive the horizontal plane; specimen cylinder axes vertical.

\section{V20-88}
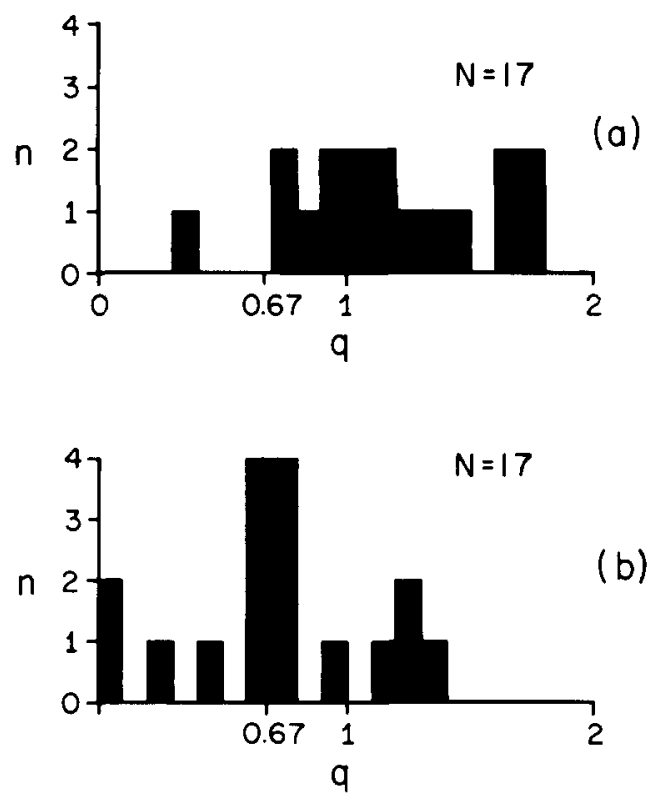

uniformly near vertical while the $K_{\min }$ axes lay in the horizontal plane (Fig. 2a). The values of the $q$ parameter were with only one exception greater than 0.67 (Fig. 3a); the average anisotropy, $h$, was $1.1 \%$. All specimens had residual errors less than $15 \%$.

During the course of these measurements, it was noticed that some specimens with $K_{\max }$ directions farthest from vertical also had the smallest length to diameter ratios, close to unity. To test this observation further, a few millimeters were shaved from the ends of the cylindrical specimens to give each a length to diameter ratio of about 0.85 . Remeasurement of their susceptibility anisotropy on the spinner magnetometer

Fig. 3. Distribution of the parameter, $q$, in specimens from core V20-88 as measured on the PAR-SM1 spinner magnetometer. (a) Length to diameter ratio of cylinder specimens greater than 1.0. (b) Same specimens but with length to diameter ratios equal to 0.85 . Values of the $q$ parameter less than (greater than) 0.67 indicate dominantly oblate (prolate) susceptibility ellipsoids. 

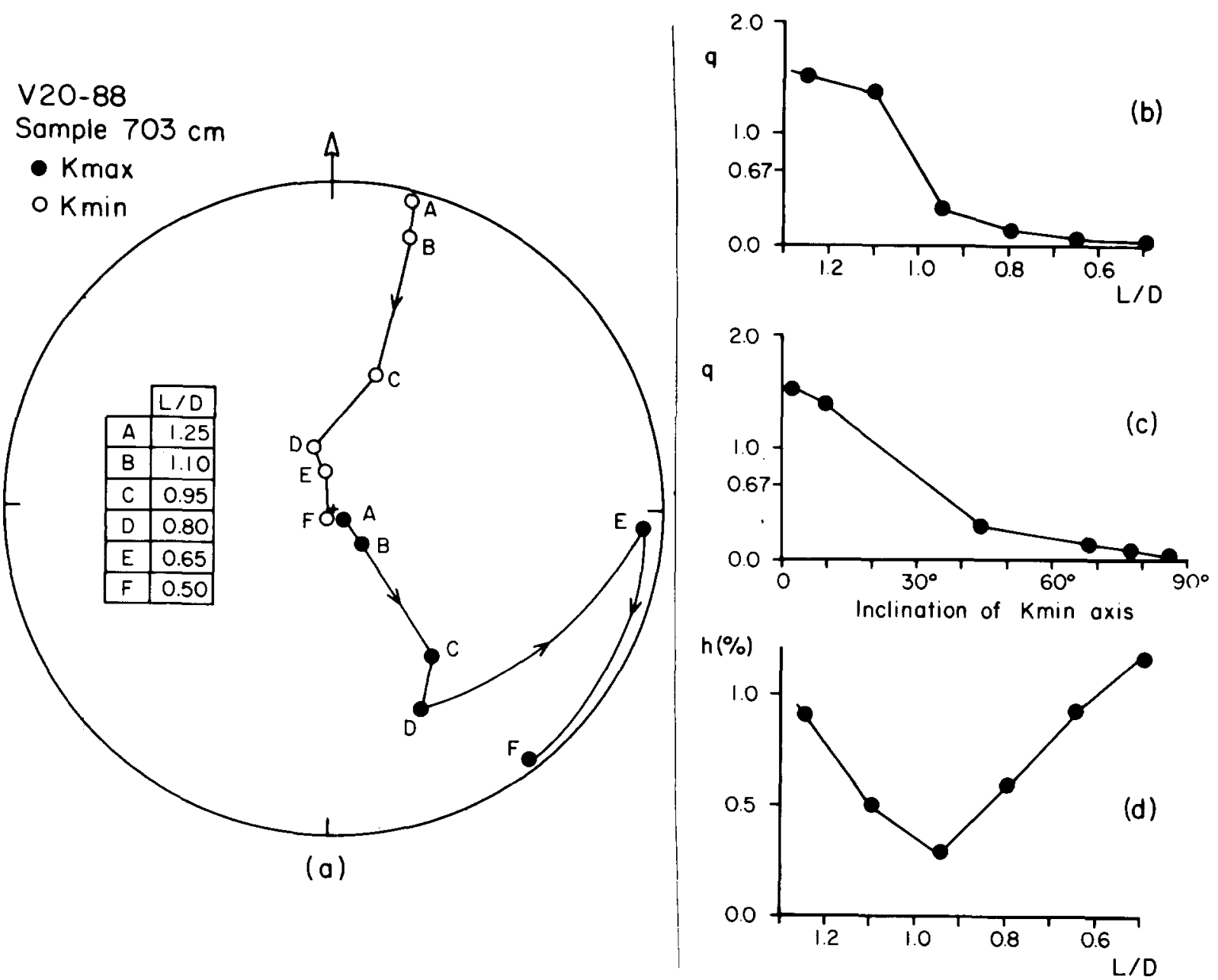

Fig. 4. Variation on susceptibility anisotropy measured on PAR-SM1 spinner magnetometer, with length to diameter ratio of cylindrical specimen from core V20-88. (a) Directions of maximum and minimum susceptibility axes plotted on equal-area projection (primitive the horizontal plane; specimen cylinder axis vertical). (b) $q$ parameter against length to diameter ratio $(L / D)$. (c) $q$ parameter against inclination of minimum susceptibility $\left(K_{\min }\right)$ axis. (d) Percentage anisotropy, $h$, against length to diameter ratio $(L / D)$.

yielded different results than originally obtained. The $K_{\max }$ and $K_{\min }$ virtually interchanged in orientation so that the $K_{\min }$ axes were usually near vertical and the $K_{\max }$ axes were mostly in the horizontal plane (Fig. 2b). In addition, the susceptibility ellipsoids were more equally distributed between oblate and prolate types (Fig. $3 \mathrm{~b}$ ) and the anisotropies, $h$, averaged only about $0.6 \%$. Three specimens, one from near the top and two from near the bottom of the core, still had near-vertical $K_{\max }$ directions.

In another experiment, the anisotropy of a cylin- drical specimen from this core was measured after successive changes in its length to diameter ratio $(L / D)$ The susceptibility ellipsoid of the specimen changed progressively from a vertical-prolate type at $L / D=$ 1.25 to one that was horizontal-oblate at $L / D=0.50$ as illustrated by the steepening $K_{\min }$ axis direction and the decrease in the value of the $q$ parameter (Fig. $4 \mathrm{a}, \mathrm{b}, \mathrm{c})$. The percentage anisotropy, $h$, reached its lowest value at a length to diameter ratio of about unity and was about 3 or 4 times greater at the highest and lowest values of $L / D$ (Fig. 4 d). 


\section{Torque meter results}

The susceptibility anisotropy of the seventeen specimens taken from V20-88 were also measured using a torque meter. Five torque readings at $45^{\circ}$ increments about each of the three specimen axes were taken in an alternating field of 70 Oe RMS. Four specimens were rejected from further consideration due to high residual errors. The susceptibility ellipsoids determined by this instrument for the remaining specimens were generally oblate: $q$ values were mostly

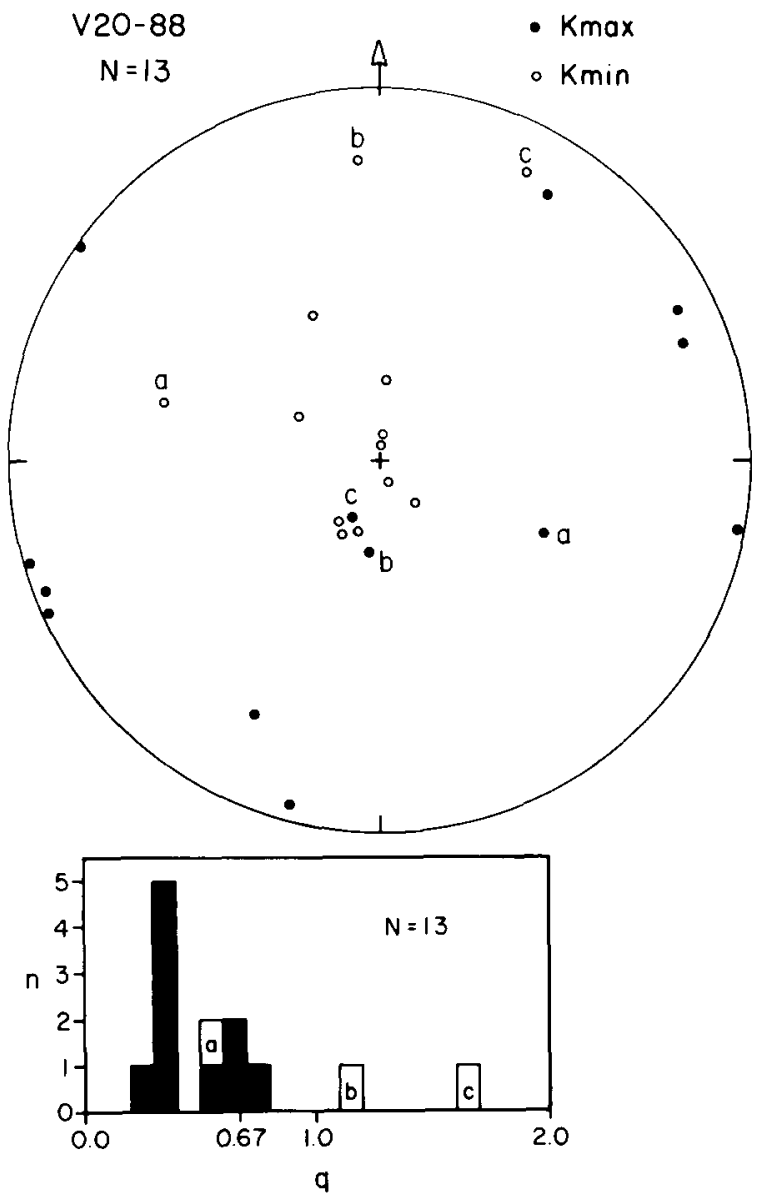

Fig. 5. Directions of maximum $\left(K_{\max }\right)$ and minimum $\left(K_{\min }\right)$ susceptibility axes as determined on torque meter of specimens from core V20-88. Axes plotted on equal-area projection with primitive the horizontal plane. Histogram shows distribution of the $q$ parameter for these specimens. Sample labelled " $a$ " from near top of core $(86 \mathrm{~cm})$; samples labelled "b" and "c" from base of core ("flow-in" section, see text). less than 0.67 while the $K_{\min }$ axes were somewhat scattered but near the vertical, except for three specimens $(a, b$ and $c)$ from near the top and bottom of the core which had anomalous anisotropies (Fig. 5).

Unlike with the PAR-SM1 spinner, no significant effect of sample shape on the measured anisotropy was detected on the torque instrument. This is illustrated by the results of successive measurements on a cylindrical specimen from the core whose leingth to diameter ratio was changed in three steps, from 1.4, 1.0 and to 0.75 (Fig. 6). While the anisotropy apparently changed with sample shape when measured on the spinner magnetometer, internally consistent anisotropy directions and magnitudes, regardless of specimen shape, were obtained with the torque instrument. Clearly, the cause of the observed shape dependency of anisotropy must be related to the different principles of measurement with the different instruments.

Additional anisotropy measurements were made on specimens from two other deep-sea sediment piston cores, RC1 1-170 and RC14-14, using the torque meter

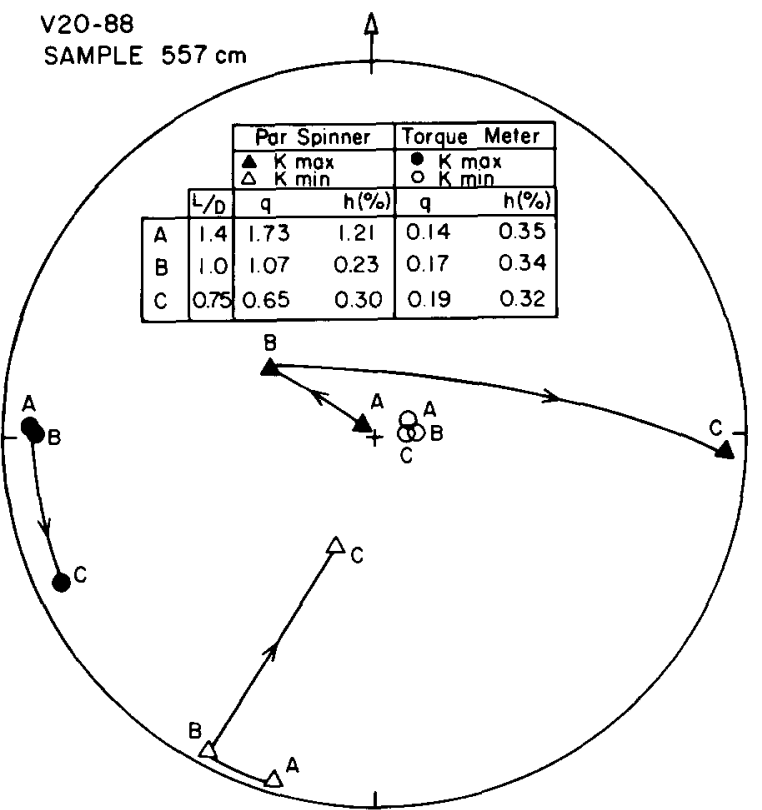

Fig. 6. Variation in susceptibility anisotropy with length to diameter ratio of cylindrical specimen from core V20-88 as observed on two different instruments. Equal-area projection with primitive the horizontal plane; specimen cylinder axis vertical. 


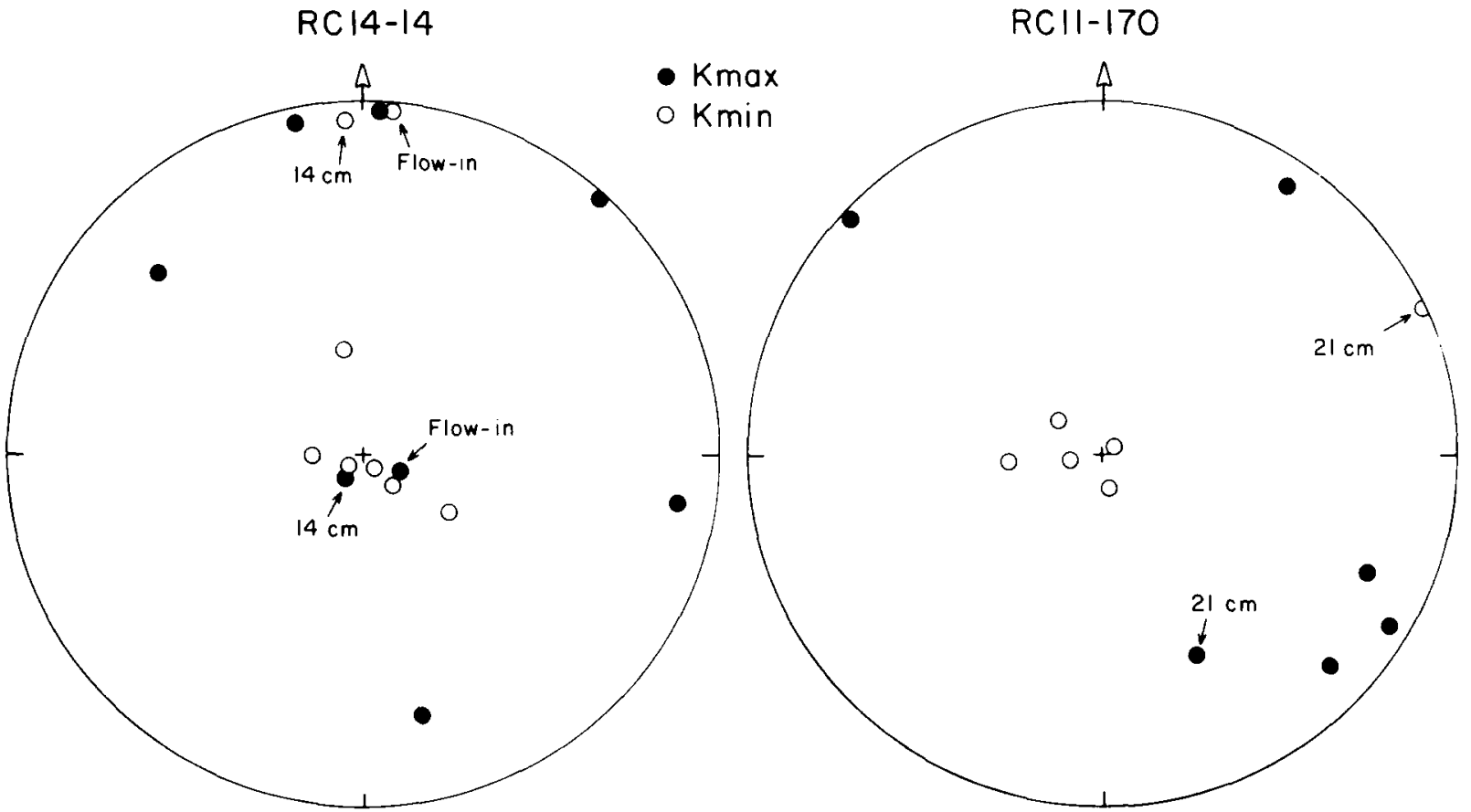

Fig. 7. Directions of maximum $\left(K_{\max }\right)$ and minimum $\left(K_{\mathrm{min}}\right)$ susceptibility axes in specimens from core RC14-14 and RC11170. Anisotropy measurements made on torque meter. Axes plotted on equal-area projection with primitive the horizontal plane. Depth in core of select specimens shown ("flow-in" occurred at base of core RC14-14 but was not identified in RC11170 ; see text).

Core RC11-170 was described by Opdyke and Foster [14] and core RC14-17 by Opdyke et al. [16]. This information is summarized in Table 1. Both cores contained sediment that generally showed evidence of burrowing by benthic organisms. Based on thermomagnetic and X-ray analysis of magnetic extracts from the cores, magnetite and titanomagnetite were the dominant magnetic minerals in each core $[16,17]$ al though the magnetic minerals in RC11-170 may have suffered some degree of low-temperature oxidation.

Almost half of the specimens from each core were rejected because of high residual errors. Most of the remaining specimens from these two cores had weak primary magnetic fabrics, characterized by oblate susceptibility ellipsoids ( $q$ averaged less than 0.67 ; Table 2) with $K_{\min }$ axes oriented near vertical (Fig. 7). Important exceptions were specimens from near the tops and/or from the bottoms of the cores; the anisotropies of these specimens were usually represented by prolate ellipsoids ( $q$ greater than 0.67 ) or more oblate types but with $K_{\min }$ axes near to the horizontal plane.

\section{Instrumental source of anomalous anisotropy}

Although the susceptibility ellipsoid as measured on the spinner magnetometer appeared to be directly related to the shape of the specimen, this cannot be due to a true shape effect of the sample as discussed, for example, by Porath et al. [18]. This is because for a body which is intrinsically isotropic magnetically, the expected susceptibility anisotropy due to its shape alone is proportional to the square of its bulk susceptibility. For such a body, the shape-induced susceptibility anisotropy, $\Delta K$, can be estimated by [4]:

$\Delta K=\frac{K^{2}\left(N_{\mathrm{a}}-N_{\mathrm{b}}\right)}{\left(1+N_{\mathrm{a}} K\right)\left(1+N_{\mathrm{b}} K\right)}$

where $K$ is the bulk susceptibility and $N_{\mathrm{b}}$ and $N_{\mathrm{a}}$ are the demagnetizing factors along the long axis and in 
any direction in the perpendicular plane, respectively, of an ellipsoid of revolution. The maximum anisotropy will occur for a needle-shaped body with $N_{\mathrm{a}}=2 \pi$ and $N_{\mathrm{b}}=0$ [19]:

$\Delta K_{\max }=K^{2} \frac{2 \pi}{1+2 \pi K}$

For bulk susceptibilities of $10^{-4}$ to $10^{-6} \mathrm{cgs}$, such as s studied here (Table 2), the maximum susceptibility anisotropy due to sample shape alone would be at most from about $6 \times 10^{-8}$ to $6 \times 10^{-12}$. These anisotropies are much too weak to account for the anomalous anisotropy measured in these sediments with the spinner magnetometer.

When using a remanent magnetization magnetometer at half-speed to make anisotropic susceptibility measurements, it is in principle possible that the second harmonic of any existing remanence will be included with the anisotropy signal as both will vary with the same frequency, double that of the rotation. This possibility had previously been studied prior to the investigation of L $\varnothing$ vlie et al. [2], and it had been found by progressively AF demagnetizing the NRM that no such higher harmonic remanence signal intruded the anisotropy signal. For the present study this conclusion was reinforced by giving samples isothermal remanent magnetizations in direct fields of $50 \mathrm{Oe}$ and $100 \mathrm{Oe}$ and measuring their anisotropies at successive stages of acquisition. These measurements indicated primarily an increase in the RMS residual error but little change in the shape or attitude of the best-fitting susceptibility

\section{TABLE 2}

Magnetic susceptibility anisotropy of specimens from three deep-sea sediment cores as measured on torque meter

\begin{tabular}{|c|c|c|c|c|}
\hline \multirow[t]{2}{*}{ Core } & \multirow{2}{*}{$\begin{array}{l}\text { No. of } \\
\text { speci- } \\
\text { mens* }\end{array}$} & \multicolumn{3}{|c|}{ Core averages ( \pm std. dev.) } \\
\hline & & $\begin{array}{l}K \\
\left(10^{-5} \mathrm{cgs} / \mathrm{g}\right)\end{array}$ & $\begin{array}{l}h \\
(\%)\end{array}$ & $q$ \\
\hline V20-88 & 10 & $6.0 \pm 0.9$ & $0.3 \pm 0.1$ & $0.48 \pm 0.21$ \\
\hline RC.11-170 & 5 & $7.8 \pm 2.3$ & $0.6 \pm 0.4$ & $0.38 \pm 0.11$ \\
\hline RC14-14 & 6 & $9.6 \pm 2.3$ & $1.8 \pm 0.8$ & $0.31 \pm 0.28$ \\
\hline
\end{tabular}

* Not including specimens from near top or bottom of cores or those with residual errors greater than $15 \%$. ellipsoid with higher remanent intensity.

The apparent sample shape effect observed on the spinner magnetometer must then be caused by induced magnetizations, in conjunction with the geometry of the measurement and sampling schemes. To achieve high sensitivity in remanence measurements the detector (pick-up coil or flux-gate sensor) of a spinner magnetometer is placed close to the specimen. On the other hand to achieve good field uniformity the field coils of a torsion magnetometer are relatively far from the specimen.

A tentative explanation of the anomalous anisotropy results obtained from the spinner magnetometer is possible even when the sample is otherwise isotropic. For example, when an isotropic, elongate cylindrical sample (Fig. 8a) is placed in an inducing magnetic field, its magnetization may be considered in three parts. A magnetic moment $m_{0}$ is induced in the central part of the sample, whose length $l_{0}$ corresponds to the ideal length/diameter ratio for which no sample-shape effect is observed; $m_{0}$ is located at the center of the sample. Because the real length of the sample, $l$, is longer than $l_{0}$, there will also be two equal contributions to the sample magnetic moment from the extra parts at each end. These are represented by magnetic moments $m$ located at the center of each end portion.

If a sensor is placed at A the geometry of the magnetic moments $m_{0}$ and $m$ to the detector is different in the $0^{\circ}$ position (Fig. $8 \mathrm{a}$ ) than in the $90^{\circ}$ position (Fig. 8b). This difference in induced magnetization appears as a signal with an in-phase component and zero quadrature component if the sample is isotropic. According to the spinner method of measurement [12], the effect appears as an apparent anisotropy difference: $\left(K_{i i}-K_{j j}\right)$.

Analysis of the magnetizations in the two configurations of Fig. 8 gives:

$\frac{\text { anomalous anisotropy }}{\text { intrinsic anisotropy }}=15(\mathrm{~s} / \mathrm{x})^{2}(\mathrm{~m} / \Delta K)=C \frac{\Delta l / l_{0}}{\Delta K / K}$ where $C=7.5(s / x)^{2}, K$ is the bulk susceptibility, $\Delta K$ is the intrinsic susceptibility difference in the measurement plane, $\Delta l=l-l_{0}$ and the other quantities are as in Fig. 8. The relative importance of the anomalous anisotropy is determined by the instrumental constant $C$, by $\Delta l / l_{0}$ and $\Delta K / K$. If the percentage anisotropy $\Delta K / K$ is very low it is possible for the anoma lous anisotropy to be dominant if the length excess 
(a)

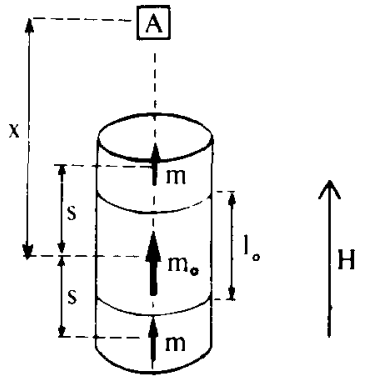

$0^{\circ}$ Position

(b)

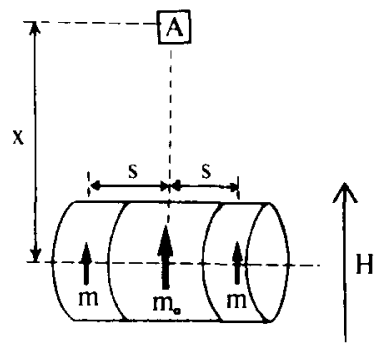

$90^{\circ}$ Position

Fig. 8. An elongate cylinder subdivided into a central region of ideai length $l_{0}$ compared to the diameter. The field $H$ induces a magnetic moment $m_{0}$ in the central region, and magnetic moments $m$ in each end excess located at distance $s$ from the sample center. The orientations and distances of the end portions from a detector at $A$, a distance $x$ from the center, are different in the $0^{\circ}$ position (a) and the $90^{\circ}$ position (b).

compared to the ideal value is large enough.

This apparent anisotropy is only found when the rotation axis is perpendicular to the cylinder axis of the sample, and the length/diameter ratio is non-ideal. When the sample spins about the cylinder axis, there is no anomalous signal provided that there is no shape asymmetry about this axis. The net effect is to create an apparent anisotropy ellipsoid which for an elongate (flattened) sample has the maximum (minimum) axis parallel to the cylinder axis. The spurious anisotropy is superposed on the anisotropy ellipsoid resulting from the magnetic fabric of the sample. If this intrinsic magnetic fabric is very weak, as in many deep-sea sediments, the sample shape effect can dominate. The directions of the magnetic susceptibility ellipsoid axes are then controlled by the attitudes of the sample axes.

\section{Discussion of magnetic fabric of deep-sea sediment}

Only a small number of magnetic anisotropy studies have been published on deep-sea sediments. We feel that the reported vertically prolate magnetic fabrics should be regarded with caution. Two possible explanations can account for these anomalous magnetic fabrics: (1) the originally reported vertically prolate fabric [1], while real, was not a representative one for deep-sea cores but may have been affected by soft sediment disturbance, and (2) the fabrics reported by L $\phi$ vlie et al. [2], made with a spinner magnetometer, may have been affected by the sample-shape effect described in this paper. The reported anomalous fabrics are therefore attributed by us to measurement and deformation effects that were unsuspected at the time of the earlier deep-sea sediment investigations.

\subsection{Anomalous anisotropy resulting from soft sedi- ment deformation}

The suggestion that deformation may have influenced the results of Harrison and Peterson [1] is supported by evidence from our own results and by others. For example, Rees and Fredericks [20] found that only 15 of 119 samples from 21 drill sites from Deep Sea Drilling Project Legs 1-6 had primary fabrics, and the majority of the remainder were influenced by deformation.

Harrison and Peterson's observations of vertically prolate susceptibility ellipsoids were made on a torque meter, similar to the instrument used in this study, and so should provide reliable data. However, the specimens which possessed this anomalous anisotropy were from the top few decimeters of their two cores; anomalous magnetic fabrics also were observed in specimens from near the top of each of the three cores examined in the present study. The uppermost layer of deep-sea sediment is often incohesive due to the high water content. This would allow preferential disturbance of the sedimentary fabric of this uppermost layer in the process of coring. Disturbance may occur during the initial impact of the coring tube with the sediment [21]; the soupy upper portion of the sediment core also has a tendency to settle and flow when the sediment-laden corer is retrieved and laid in a horizontal position for extrusion or storage. Therefore, the anomalous susceptibility anisotropies measured near to the 
tops of sediment cores by Harrison and Peterson and in this study may reflect reorientation of sediment particles caused by coring disturbances and not necessarily the magnetic fabric this sediment may have possessed in situ.

Harrison and Peterson [1] suggested that the anomalous magnetic fabric in their two cores was in some way due to authigenic magnetic minerals although, as L $\phi$ vlie et al. [2] pointed out, it is not apparent why the in-situ formation of magnetic minerals should result in a vertically prolate susceptibility ellipsoid. The occurrence of anomalous magnetic fabrics near to the tops of each of the three cores studied here, some of which contained magnetic minerals most likely detrital in origin, supports the interpretation of these anomalous magnetic fabrics as due to coring disturbances.

Anomalous susceptibility anisotropies were also observed in the obviously disturbed "flow-in" sections present at the base of two cores in this study. "Flow-in" consists of sediment that has been drawn into the coring pipe by additional upward movement of the piston, and often, as in two of the cores studied here, has a visible vertically oriented pattern which distinguishes it from sediment cored in situ [22]. The vertically prolate susceptibility ellipsoids observed in specimens of "flow-in" sediment undoubtedly reflect sediment particle reorientation in the vertical flow structure.

Although "flow-in" has been identified most commonly at the bottom of some piston cores (e.g. [23]), it is possible for it to occur within, or even at the top of the core, depending upon the motion of the piston during coring (F.W. McCoy, personal communication 1975). Moreover, coring disturbances may not be clearly visible in some sediments and other techniques, such as X-ray radiography, may need to be employed to identify the disturbed sections [23]. The occurrence of anomalous magnetic fabrics in sections of cores thought to be influenced by coring disturbances suggests that susceptibility anisotropy analysis may provide another technique to distinguish these disturbed sections from those that have well-preserved in-situ fabrics.

\subsection{Anomalous anisotropy resulting from sample shape}

In samples with weak intrinsic magnetic fabrics in which the sample shape effect described in this paper can dominate, the directions of the principal susceptibility axes reflect the orientations of the sample axes. In many of the samples of L $\phi$ vlie et al. [2] the cylinder axes were vertical. Thus, the sample shape effect resulted in vertically prolate magnetic fabrics for most of their cores.

L $\phi$ vlie et al. did find anisotropies consistently in the form of horizontally oblate susceptibilities in specimens from two sediment cores as well as from redeposited sediment form cores that originally gave vertically prolate susceptibilities. The percentage anisotropy, $h$, in these specimens was on average greater than in the others they measured, suggesting that the signal due to the magnetic fabric was able to dominate over that due to the apparent sample shape effect. We also noticed that the direction of the principal susceptibility axes in three specimens from core V20-88 (Fig. 1) did not change appreciably with change in specimen shape; these specimens had higher anisotropies (several percent) than had the remaining specimens from the core (less than one percent).

The susceptibility anisotropy of specimens from the intervening section of the three cores examined in the present study can be interpreted as vestiges of a primary magnetic fabric. The anisotropies were usually weak, less than a few percent (Table 2) with a dominant foliar element close to the horizontal plane. It is likely that any original magnetic fabric in these sections has been reduced in magnitude by post-depositional bioturbation and this may account in part for the apparently high measurement errors observed for many specimens. Here again, the weakness of the intrinsic anisotropies in these deep-sea sediments allowed the apparent sample shape effect to dominate the signal measured with the spinner magnetometer.

\section{Discussion and conclusions}

The above interpretation of the anisotropy is consistent with the fine-grained nature of most deep-sea sediment $[2,15]$ in which a natural remanent magnetism (NRM) is believed to be acquired by post-depositional alignment of detrital magnetic grains [24,25]. The finest-sized fraction of magnetic grains may be oriented preferentially by the magnetic field at high interstitial water contents, producing the NRM, while any larger magnetic grains may be less mobile, better 
preserving their physical orientation at the time of deposition and giving rise to an excess of susceptibility in the horizontal plane. Subsequent bioturbation of the sediment still can allow magnetic orientation of the finest-grained magnetic fraction to produce an NRM [24] but may randomize any shape-dependent orientation of the larger grains, reducing any primary magnetic fabric. Whether the sediment has been affected by bioturbation or not, the small observed susceptibility anisotropies should not produce any significant deviation (e.g., inclination error) in the direction of NRM.

Erratic NRM directions, often observed near to the tops of deep-sea sediment cores [26] can be attributed to the same physical disturbance of the sediment during the coring operation that is believed responsible for the anomalous susceptibility anisotropies. Similarly, useful directions of NRM are not obtained from the obviously disturbed "flow-in" section of deep-sea sediment cores: steep inclination directions of NRM, unrelated to the magnetic field at the core sites, characterized the "flow-in" sections of cores V20-88 and $\mathrm{RC} 14-14$. In contrast, the close general agreement found between expected and observed remanent inclinations in the intervening section of these deep-sea sediment cores $[14,16]$ coincide with weak, but more normal, sedimentary magnetic fabrics.

The present study has led to the following principal conclusions:

(1) The susceptibility anisotropies of reliable specimens taken from three deep-sea sediment cores were weak, less than a few percent of the average bulk susceptibility, and usually could be represented geometrically as oblate ellipsoids with $K_{\min }$ axes near to the vertical. These anisotropies reflect the magnetic fabric of the sediment acquired as a result of depositional processes, including bioturbation.

(2) Susceptibility anisotropies that differ substantially from the above were often found in specimens from the very tops or bottoms of the cores and are best explained as due to sediment disturbance in the coring procedure. Prolate susceptibility ellipsoids with near-vertical $K_{\max }$ axes were consistently found in the "flow-in" sections near the base of these cores and sometimes in apparently disturbed sections near the tops of the cores as well.

(3) Previous reports of vertically prolate susceptibility ellipsoids as the dominant form of magnetic anisotropy in deep-sea sediments can probably be ascribed to either sampling of sediment affected by coring disturbances or to an artifact such as an apparent sample shape effect, which can influence spinner magnetometer observations.

\section{Acknowledgments}

We are grateful to A.I. Rees for providing us with the principal parts of a torsion magnetometer. We also thank N.D. Opdyke and F.W. McCoy for their critical reading of the manuscript and M.N. Israfil for his assistance in the operation of the torque meter. The figures were drafted by M. Alvarez; J. Champeau and I. Earl typed the several versions of the manuscript.

This research was supported by National Science Foundation Grant GA36190. Support for collecting and curating the cores was supplied through National Science Foundation Grant DES72-01568 and Office of Naval Research Grant N00014-75-C-0210.

\section{References}

1 C.G.A. Harrison and M.N.A. Peterson, A magnetic mineral from the Indian Ocean, Am. Mineral. 50 (1965) 704.

2 R. L $\phi$ vlie, W. Lowrie and M. Jacobs, Magnetic properties and mineralogy of four deep-sea cores, Earth Planet. Sci. Lett. 15 (1971) 157.

3 L. Granar, Magnetic measurements on Swedish varved sediments, Arkiv Geofysik 3 (1958) 1.

4 A.l. Rees, The use of anisotropy of magnetic fabric in paleocurrent estimation of sedimentary fabric, Sedimentology 4 (1965) 257.

5 N. Hamilton and A.I. Rees, The use of magnetic fabric in paleocurrent estimation, in: Paleogeophysics, ed. S.K. Runcorn (1970) 445.

6 A.I. Rees, The effect of water currents on the magnetic remanence and anisotropy of susceptibility of some sediments, Geophys. J. 5 (1961) 235.

7 A.I. Rees, The effect of depositional slopes on the anisotropy of magnetic susceptibility of laboratory depositional sands, J. Geol. 74 (1966) 856.

$8 \mathrm{G}$. Ising, On the magnetic properties of varved clay, Arkiv Matematik, Astron. Fys. 29A (1942) 1.

9 J.W. Graham, Significance of magnetic anisotropy in Appalachian sedimentary rocks, in: The Earth Beneath the Continents, Am. Geophys. Union Monograph 10, eds. J.S. Steinhart and T.J. Smith, (1967) 627.

10 A.I. Rees, U. von Rad and F.P. Shepard, Magnetic fabric of sediments from the La Jolla submarine canyon and fan, California, Mar. Geol. 6 (1968) 145. 
11 N.D. Opdyke and K.W. Henry, A test of the dipole hypothesis, Earth Planet. Sci. Lett. 6 (1969) 139.

12 H.C. Noltimier, The use of the spinner magnetometer for anisotropy measurements, in: Methods in Paleomagnetism, Developments in Solid Earth Geophysics 3, eds. D.W. Collinson, K.M. Creer and S.K. Runcorn (Elsevier, Amsterdam, 1967) 399.

13 R.F. King and A.I. Rees, The measurement of the anisotropy of magnetic susceptibility of rocks by the torque method, J. Geophys. Res. 67 (1962) 1565.

14 N.D. Opdyke and J.H. Foster, Paleomagnetism of cores from the North Pacific, in: Geological Investigations of the North Pacific, Geol. Soc. Am. Mem. 126 (1970) 83.

15 D.V. Kent and W. Lowrie, Origin of magnetic instability in sediment cores from the central North Pacific, J. Geophys. Res. 79 (1974) 2987.

16 N.D. Opdyke, D.V. Kent and W. Lowrie, Details of magnetic polarity transitions recorded in a high deposition rate deep-sea core, Earth Planet. Sci. Lett. 20 (1973) 315.

17 D.V. Kent, Magnetic mineralogy and magnetic properties of deep-sea sediments, Ph.D. Dissertation, Columbia Univ., N.Y. (1974).

18 H. Porath, F.D. Stacey and A.S. Cheam, The choice of specimen shape for magnetic anisotropy measurements of rocks, Earth Planet. Sci. Lett. 1 (1966) 92.

19 T. Nagata, Rock Magnetism (Maruzen, Tokyo, 1961) 2nd ed., 350 .

20 A.I. Rees and D. Fredericks, The magnetic fabric of samples from the Deep Sea Drilling Project, Legs 1-6, J. Sediment. Petrol. 44 (1974) 655.

21 F.W. McCoy and R.P. Von Herzen, Deep-sea corehead camera photography and piston coring, Deep-Sea Res. 18 (1971) 361 .

22 D.B. Ericson, M. Ewing, G. Wollin and B.C. Heezen, Atlantic deep-sea sediment cores, Geol. Soc. Am. Bull. 72 (1961) 193.

23 A.H. Bouma and J.A.K. Boerma, Vertical disturbances in piston cores, Mar. Geol. 6 (1968) 231.

24 D.V. Kent, Post-depositional remanent magnetization in deep-sea sediment, Nature 246 (1973) 32.

25 R. L $\phi$ vlie, Post-depositional remanent magnetization in a redeposited deep-sea sediment, Earth Planet. Sci. Lett. 21 (1974) 315.

26 N.D. Opdyke, The paleomagnetism of oceanic cores, in: The History of the Earth's Crust, ed. R.A. Phinney (1968) 61. 